\title{
Research and Practice of Meta-synthesis Management for the Government-led Urban Complex Construction Project
}

\begin{abstract}
This paper researches the overall construction target of government-led urban complex construction projects based on the perspective of sustainable urban development. In order to achieve benefit maximization, the meta-synthesis management for the government-led urban complex construction project is studied. In order to combine theory and practice, several typical government-led urban complex construction project cases, such as Guangzhou Higher Education Mega Center and Guangzhou International Financial City etc. are examined. These examples point to the feasibility of government-led meta-synthesis management and demonstrate the benefits that can be achieved through this model.
\end{abstract}

Keywords: government-led construction project, urban complex, meta-synthesis management, sustainable development, benefit maximization

\section{The role and characteristics of the gov- ernment-led urban complex construction proj- ects in urban development}

1.1 The role of the government-led urban complex construction projects

Government-led urban complex construction projects are fixed-asset construction projects in by the government. These projects aim to adapt and promote the development of the national or regional economy, to meet the cultural and social needs of the affected population, as well as account for political and defense considerations. Construction projects of a certain size and with area comprehensive service

Manuscript received December 3, 2013; accepted March 3, 2014

Ru-gui Chen ( $\square)$

Guangzhou Municipal Government, Guangzhou 510030, China

Email: chenrg@gz.gov.cn

Jia-meng Chen

Guangzhou Administration Office of Major Public Construction Projects, Guangzhou 510006, China functions can play a huge role in promoting urban economic development, speeding up urban construction and enhancing the city's comprehensive competitiveness (Zhang, 2009):

(1) Promoting urban economic development. Government financing, private funding and foreign investment are attracted during the construction or after the completion of the government-led urban complex construction projects. This can result in both collective effects and radiation effects, enlarging the investment returns of the project and promoting the economic development of the city.

(2) Speeding up urban construction. Typically, urban construction efforts coalesce around a few major projects, since projects of this type can stimulate market potential and bring together social capital. They are also of outstanding significance regarding urban development and spatial expansion.

(3) Enhancing the city's comprehensive competitiveness. Government-led urban complex construction projects, especially those with a certain scale and serving a wide array of functions for the local community, can not only provide an unparalleled platform for urban or regional development, but also create a favorable investment environment attracting capital, projects and talents. In addition, these projects can greatly enhance the city's image and improve the quality of people's lives.

1.2 The characteristics of the government-led urban complex construction projects

The construction management process of government-led urban complex construction projects is both large and complicated and is defined by following features:

(1) High level of social concern. The urban complex projects attract great concern in the community since projects of this type can affect the interests of many different parties.

(2) Large scale. In terms of the construction fund, construction sites, project amount as well as the ancillary facilities.

(3) High standards. The government-led construction projects often apply new management concepts and adopt 
new construction techniques based on the requirements of specific projects.

(4) Difficult coordination during the construction management process. Many construction units participate to deliver a large-scale project and are involved to different extents and at different stages throughout the project. This complexity can lead to conflict during the construction process and thus requires a lot of co-ordination for effective mitigation.

\section{The overall aim and benefits evaluation sys- tem of the government-led urban complex con- struction projects}

2.1 The overall aim of the government-led urban complex construction projects

Government-led urban complex construction projects should be delivered sustainably so as to effectively prevent "urban disease" and resolve the potential conflict between economic, social and environmental considerations. By applying the concept of sustainability to the construction of urban projects, a win-win-win situation can be expected with regard to economic, social, and environmental development. Current concepts of urbanization emphasize sustainability and overall efficiency, indicating that cities should be developed sustainably and vibrantly (Wen, 2010).

The overall aim of the government-led urban complex construction projects should be strategic, public welfare, instructional and demonstrative. Balanced and sustainable de- velopment should be targeted in order to achieve and maintain a high degree of harmony regarding economic development, social progress and ecological protection. A trinity concept of development should be adopted that is based on creating a low-carbon economy, progressing toward a smart city model, and improving the happiness of stakeholder groups. Effective management of government-led construction projects requires the simultaneous administration of both tangible assets (e.g. land, space, public facilities, ecological environment, etc.) and intangible assets (e.g. investment climate, brand image, history, cultural environment, etc.) (Zheng \& Xu, 2012). Regional features should be reflected during the project implementation process. By adopting the building philosophy of limiting carbon emissions and by pursuing green and smart construction, technology and nature can be fully integrated and thus provide for efficient resource allocation and conservation. Overall project objectivessuch as benefits produced, quality, safety and schedule - are suggested to be managed comprehensively so that the life cycle project performance can be effectively evaluated. By doing so, the overall efficiency of the project is expected to be maximized, which is in line with the requirements of the new urbanization. Figure 1 shows the target system of the government-led urban complex construction projects.

2.2 Benefits evaluation system of the government-led urban complex construction projects

The benefits of the government-led urban complex construction projects can be evaluated based on the construction effectiveness before project delivery as well as the benefits received after project delivery. Indicators of construction

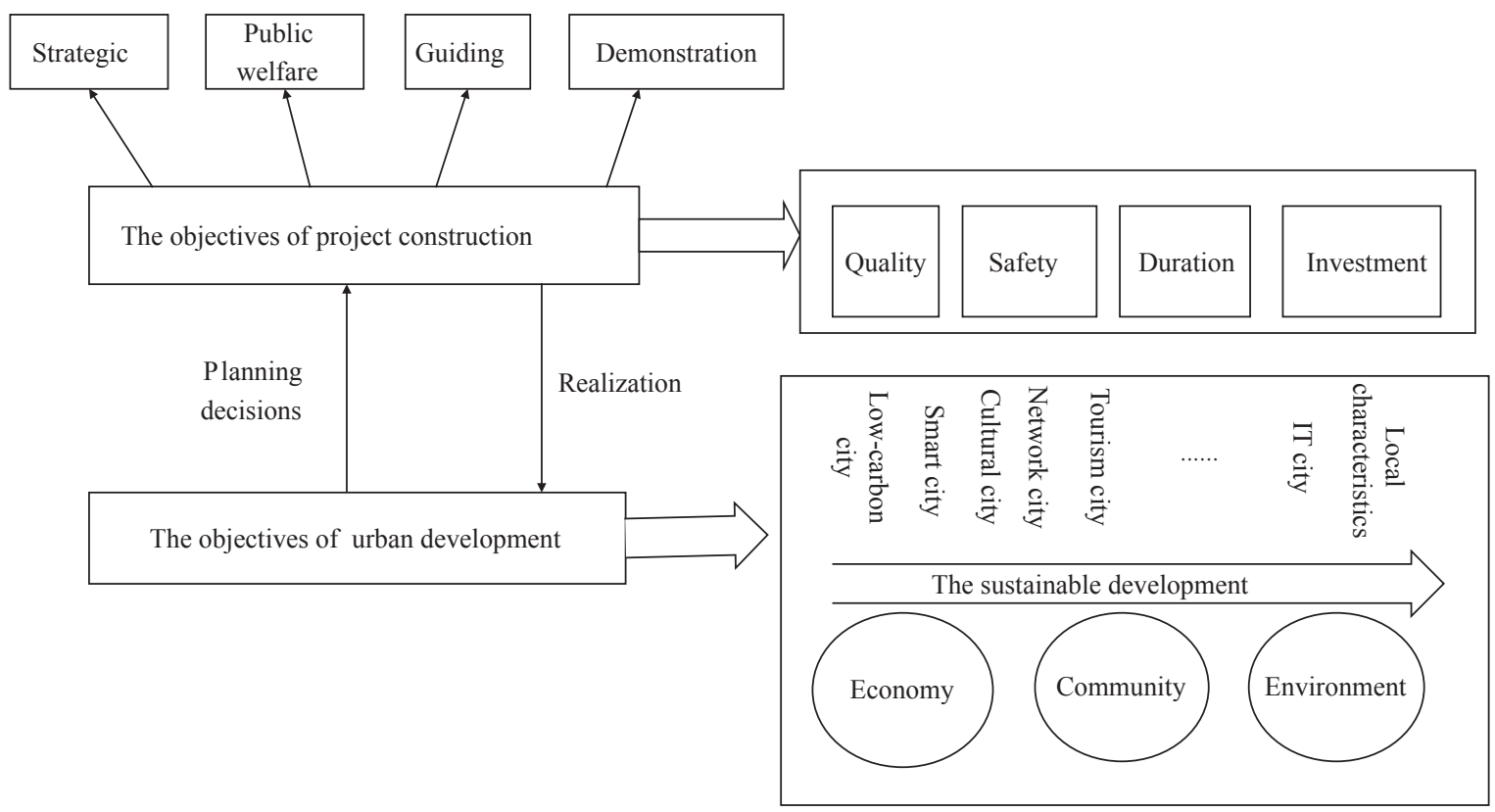

Figure 1. Target system of the government-led urban complex construction projects based on the concept of sustainable development. 
effectiveness are set to evaluate the construction project management level. These indicators measure investment decisions, fundraising and control, quality control, schedule control and safety control, etc. Indicators of running benefits, on the other hand, are primarily adopted to assess the effect of project outputs, evaluating the achievement of the project objectives from economic, social and environmental perspectives. Table 1 shows the benefits evaluation system in detail.

Table 1 Benefits Evaluation System of the Government-led Urban Complex Construction Projects

\begin{tabular}{|c|c|c|}
\hline First-class Index & Second-class Index & Third-class Index \\
\hline \multirow{19}{*}{$\begin{array}{l}\text { Construction } \\
\text { effectiveness indices }\end{array}$} & Investment decisions & The adequacy of the feasibility study \\
\hline & & The standardization and effectiveness of the investment decision-making procedure \\
\hline & & The scientific nature of the investment decision-making mechanism \\
\hline & Fund raising and control & The legality of funding source \\
\hline & & The timeliness of funds \\
\hline & & The soundness and effectiveness of financial internal control system \\
\hline & & The legality of funding use \\
\hline & & The rationality of capital expenditure structure \\
\hline & & The legitimacy of capital expenditures \\
\hline & & The increase or decrease rate of loan interest \\
\hline & & The increase or decrease rate of construction investment \\
\hline & & The rate of invalid investment and the rate of waste and loss \\
\hline & Quality control & The rate of qualified project products \\
\hline & & The rate of high-quality project products \\
\hline & Schedule control & Project completion ahead of schedule or delayed \\
\hline & & Uncompleted projects as scheduled \\
\hline & Safety control & The accident rate \\
\hline & & The personnel casualty rate \\
\hline & & The rate of economic loss \\
\hline \multirow{27}{*}{$\begin{array}{l}\text { Running benefits } \\
\text { indices }\end{array}$} & Economic benefits & The output rate of newly increased fixed assets \\
\hline & & The increasing rate of fixed assets investment \\
\hline & & The effect coefficient of fixed assets investment \\
\hline & & The delivery of fixed assets \\
\hline & & Financial net present value \\
\hline & & Financial internal rate of return \\
\hline & & Pay back period \\
\hline & & Other economic evaluation index \\
\hline & Social benefits & Contribution to GDP \\
\hline & & Contribution to the tertiary industry \\
\hline & & Contribution to transportation \\
\hline & & Employment provided (per unit investment) \\
\hline & & Employment rate in the construction area \\
\hline & & Contribution to the upgrade of industries \\
\hline & & Promotion of industrial radiation \\
\hline & & Promotion of social spiritual civilization progress \\
\hline & & Contribution to social stability and harmony \\
\hline & & Social satisfaction \\
\hline & & Social accumulation rate \\
\hline & Ecological benefits & The cost of ecological environment treatment \\
\hline & & Project pollution control \\
\hline & & The qualified rate of waste gas treatment \\
\hline & & The qualified rate of sewage treatment \\
\hline & & Occupation of cultivated land per unit investment \\
\hline & & Protection of natural resources \\
\hline & & Environmental quality index \\
\hline & & The rate of energy input/output \\
\hline
\end{tabular}




\section{Meta-synthesis management based on the overall objectives of the government-led urban complex construction projects}

To deliver government-led urban complex construction projects often requires the participation of multiple construction units. Many technical problems may emerge during the process due to the large scale of projects and the complexity of construction conditions. On the other hand, investors will not only consider the investment returns of a project, but also pursue comprehensive benefits with regard to economic, environmental and social aspects. All these characteristics point to the complexity of the construction management process. To maximize the comprehensive efficiency of the system necessitates meta-synthesis management.

3.1 Multidimensional perspective of meta-synthesis management for the government-led urban complex construction projects

With the complexity of construction projects, problems occurring in the construction management processes will range from simple management issues to complicated, systematic management issues. Accordingly, the basis of solutions to problems should evolve from standardized procedural management into systematic project management, and then into meta-synthesis management.

Resources of the government-led urban complex construction projects are suggested to be systematically integrated so as to achieve the anticipated project objectives and to maximize investment benefits. Figure 2 illustrates the multidimensional meta-synthesis management for the government-led urban complex construction projects with regard to the synthesis of objectives, organizations as well as procedures.

To achieve the above-mentioned multidimensional meta-synthesis management for the government-led urban complex construction projects necessitates the adoption of the following concepts (Hao, 2009):

(1) The concept of multi-objective integration. The project should be delivered with quality and safety as prerequisites and cost control as an objective. The requirements of environmental protection and technological innovation should be comprehensively considered to make sure the project is completed on time so the integrated project aim can be realized.

(2) The concept of project life cycle. The interests of diverse stakeholder groups together with the overall benefits throughout the project life cycle should be thoroughly considered based on different project phases, e.g. pre-planning, preparation and construction, operations and maintenance, etc.

(3) The concept of risk/benefit sharing. An information sharing platform based on strategic alliances is recommended for achieving the dynamic meta-synthesis management. Partnerships can be then established by adopting the philosophy of risk/benefit sharing.

(4) The concept of harmonious development. Urban complex construction projects do not only embody material wealth and cultural heritage, but are also products of science, technology and art. Their construction should be in line with city planning and urban transportation requirements, complementing the surrounding environment, embodying urban functions, including geographical and cultural

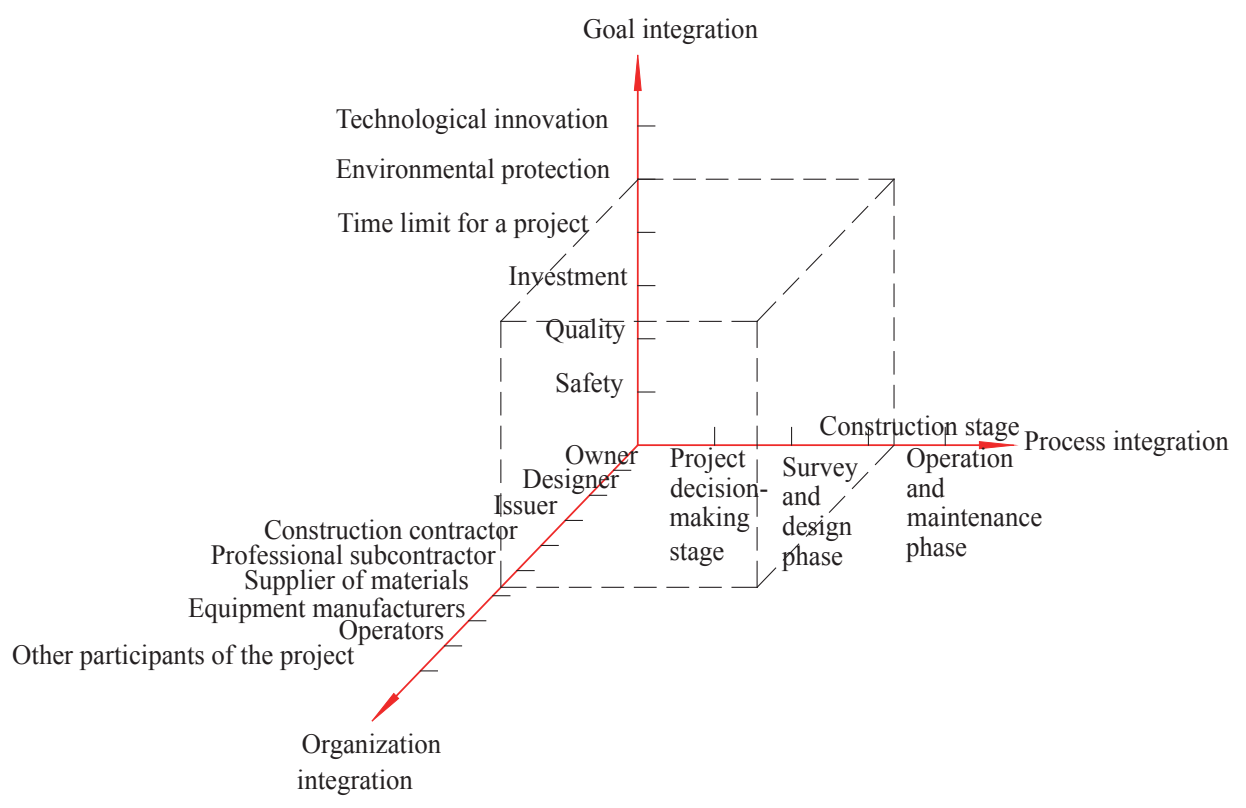

Figure 2. Multidimensional perspective of meta-synthesis management. 
characteristics, and adapting to the requirements of sustainable development.

(5) The concept of integrated effect. The overall effectiveness of an integrated body is greater than the simple sum of efficacy of its individual elements. Different elements interact, aggregate and recombine when forming an integrated body, and through this process the overall functions of the integrated system can be greatly improved. This principle of integrated effect has revealed the advantages of the meta-synthesis management to strengthen the functions of the overall system.

3.2 Synthesis of objectives of the government-led urban complex construction projects

The relationships between safety, quality, schedule and cost are suggested to be handled dynamically so that their conflicts can be better resolved in the project implementation process. Attention should also be paid to other issues such as risk management, energy-saving, and environmental protection, with the aim of successfully achieving the overall objectives of the project. Figure 3 shows the system of objective synthesis.

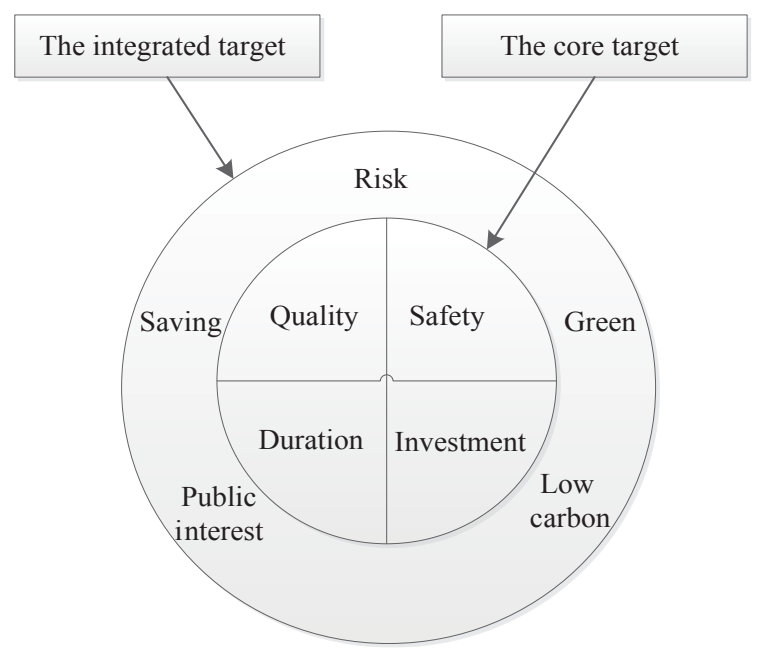

Figure 3. The system of objective synthesis of the government-led urban complex construction projects.

Project safety must be controlled, including the safety of project production, construction workers as well as surrounding personnel.

Project quality must be first-rate, with regard to the quality of the engineering entity together with the overall functions, technical standards and safety of the project system. The consistency is pursued between the quality of work, project and product/service throughout the project cycle.

Project cost must be controlled throughout the whole project life cycle. Both the construction cost and the maintenance cost should be comprehensively considered.
The project schedule must be controlled from project initiation to project completion.

The project must maintain an emphasis on environmental protection, focusing on the coordination between the construction projects and the natural and human environment. Attention should also be paid to other issues such as energy saving, emission reduction, etc.

Technological innovation should be vigorously promoted when delivering urban complex construction projects. Scientific and advanced design ideas, construction techniques and management methods should also be widely applied.

3.3 Synthesis of organizations of the government-led urban complex construction projects

The government-led urban complex construction projects involve multiple participating parties, including government departments, construction, design, supervision and equipment installation companies as well as engineering consultants, tender agents, project evaluation organizations, etc. To manage the organizational relationships of these concerned units necessitates the establishment of the project breakdown structure (PBS), organization breakdown structure (OBS) and work breakdown structure (WBS).

As revealed from Guangzhou's practice regarding life cycle meta-synthesis management of government-led urban complex construction projects, government construction project management organizations are now playing the role of main management bodies of projects, coordinating diverse relationships and facilitating project implementation. Government departments focus on co-ordination while professional institutions handle professional and transactional work. This can be helpful not only in promoting new plans, designs, technologies, materials and concepts but also be beneficial for the supervision and coordination of the government and thus achieve standardized management. Such a meta-synthesis management model has added to the project success of Guangzhou Higher Education Mega Center, the Asian Games City as well as the ongoing International Financial City in Guangzhou, helping control the project cost and schedule, guaranteeing the project quality and improving investment returns.

3.4 Synthesis of procedures of the government-led urban complex construction projects

\subsubsection{Synthesis of decision making and operation}

The management objective in the decision-making stage is to choose the right projects and determine the appropriate investment, while the operational phase aims to maintain project functions and control the project cost.

In the decision-making stage of the government-led urban complex construction projects, the decision makers should thoroughly consider different issues that may occur during 
project construction and operation according to the nature of the project and the diverse needs of construction and operation. The interrelations and interactions between the project itself and the macro and micro environment, project financing, the effect/strategy of urban development should also be comprehensively analyzed so as to raise and compare diverse proposals and reach the final decision.

By capturing lessons from major construction projects in China (e.g. Guangzhou) and overseas countries, the concept of parallel contracting and a development mode combining SOD (i.e. Service-Oriented Development, development led by the construction of social service facilities) and TOD (i.e. Transit-Oriented Development, development led by public transportation) were applied when delivering Asian Games City in Guangzhou. The operational phase of the project was emphasized and all project decisions were made by taking into account the needs of end users. The Guangzhou Asian Games City was constructed with aim to not only satisfy the needs of Asian Games but also serve as a core area of the future new town development. The project was also expected to bring demonstration effect with regard to the post-Games stadium utilization.

The current construction funds of urban infrastructure projects mainly come from government financing and bank loans. Such financing methods may lead to difficulty since investment in this type of project can be rather huge as revealed from the case of Guangzhou Asian Games City. As a result, parts of the project were contracted out to reduce the pressure of financial investment as well as to facilitate effective competition among diversified investors. Private capital was stimulated and mobilized from the socio-economic perspective. Through this, development of the entire area has been facilitated with reduced use of government funding.

\subsubsection{Synthesis of decision making and design}

The design phase aims to implement the investment objectives while limiting investment amounts. The optimal design proposal should be determined by thoroughly comparing different options.

Synthesis of decision-making and design stages of government-led urban complex construction projects can effectively avoid project decision-making and design being separated functions so as to eliminate the conflicts between investors and designers. This, on the one hand, allows government investors to participate in the whole process of design work so that their needs can be more accurately expressed. The partnership between the investors and the design units can therefore be strengthened. On the other hand, conflicts between actual demands and technical limitations can be properly handled so as to improve investor satisfaction with the project. Compared with other types of projects, government-led urban complex construction projects with more comprehensive planning and more difficult design require better coordination between diverse participating parties. Communication should be strengthened in the phases of decision-making and design and regular meetings are recommended as an effective mechanism for achieving meta-synthesis management of government-led urban complex construction projects.

Taking the ongoing Guangzhou International Financial City as an example, the government believes that the underground space should be fully utilized to improve the utilization rate of urban space and therefore promote the future development of the city. The overall planning area of the International Financial City is 7.5 square kilometers with 1.32 square kilometers as the starting area. The main construction work occupies 2 million square meters in underground space of the starting area, including underground transportation systems, underground commercial facilities, underground public service facilities, underground vault facilities, underground ecological facilities, underground municipal infrastructure, underground disaster prevention systems, etc. The government investors should make the right project decisions according to a thorough consideration of all the design challenges. Ensuring technical feasibility necessitates the adoption of the meta-synthesis management approach in project decision-making and design stages. In this case, some research institutes, design units as well as experts were invited to conduct studies or make comments on the relevant work. Based on the results, the investors make the final project decisions so as to effectively achieve meta-synthesis management.

3.5 Safeguard measures of meta-synthesis management for the government-led urban complex construction projects

(1) Establishing robust management systems, including the design management system, the tender management system and the construction management system, as detailed respectively in Figure 4, Figure 5 and Figure 6.

(2) Adopting a social management model predicated on the idea of "small owners, big society": maintaining capable personnel in the construction units, strengthening supervision, counseling, agency, etc; hiring professionals to carry out all professional, technical and transactional work.

(3) Developing standardized management systems, such as bidding contract management systems (i.e. measures for the administration of bidding, contract management regulations, special contract terms, etc.), construction management measures (i.e. measures for contractor management, mea-

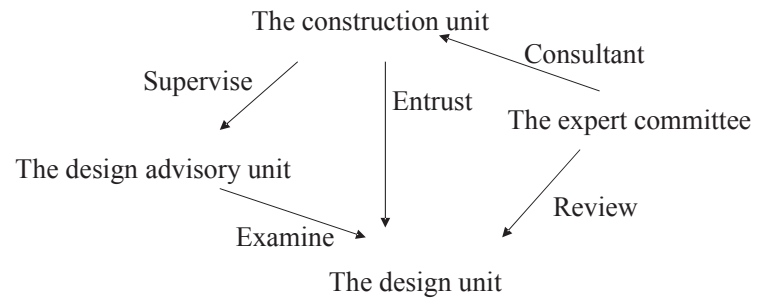

Figure 4. The design management system. 


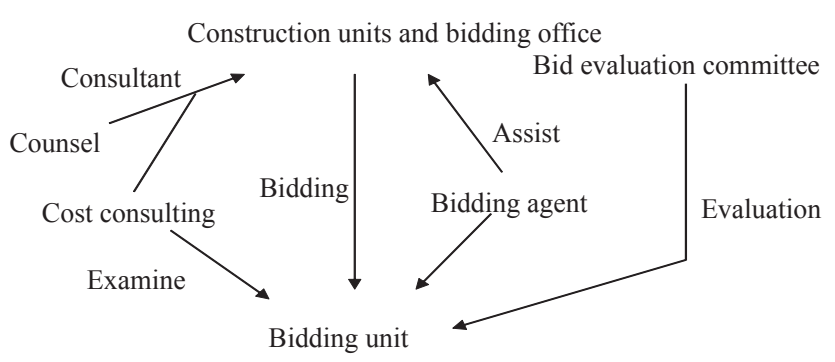

Figure 5. The tender management system. sures for construction site management, measures for project supervision, etc.), and comprehensive management measures (i.e. measures for comprehensive evaluation, design and file management, general principles for design, design change management practices, records management provisions, etc.).

(4) Using modern management tools: carrying out longterm planning through the project management information system, establishing collaborative work platform for project management based on the internet, including project man-

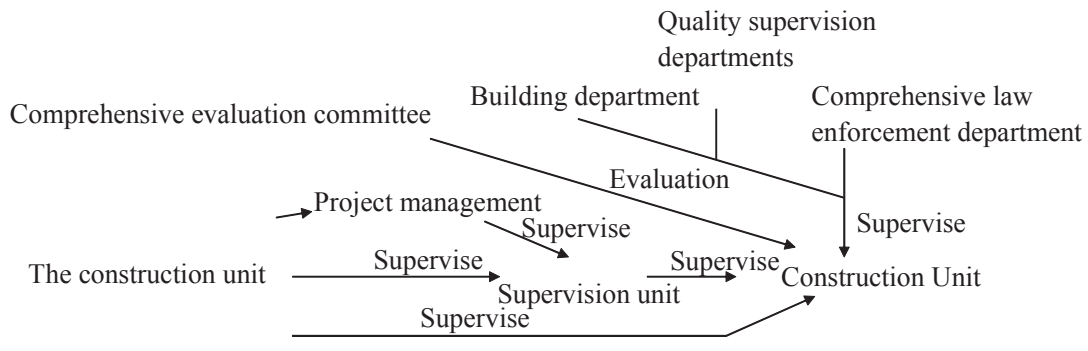

Figure 6. The construction management system.

agement information systems, project management visualization systems, multi-channel integrated information application portals, data archive center of project management, statistical analysis and knowledge base of project management, support system of project management and other project management tools. Through this, each participating party of the project can be provided with a personalized single portal for viewing project information so that the efficiency of information exchange and the effectiveness of collaborative work can be greatly improved.

\section{A typical case of meta-synthesis manage- ment for the government-led urban complex construction projects}

\subsection{Guangzhou Higher Education Mega Center}

\subsubsection{Project objectives}

Guangzhou Higher Education Mega Center was constructed with the aim to be a national first-class university park and a center for talent cultivation and scientific research in South China. The university campus area is also expected to be ecological and informational, adapting to the market economic system and the city status of Guangzhou as an internationalized regional center in the 21 st century. It will play the core role in personnel training, scientific research, high-technology industry, culture development and dissemination, tourism, etc. for not only the province of Guangdong but also the whole country of China. Through collaboration with the Science and Technology Industrial Park, optimal comprehensive benefits regarding the social, cultural and economic perspectives are expected to be obtained. This can greatly enhance the competitiveness of the city. The construction of Guangzhou Higher Education Mega Center is also important when implementing the local government's strategy of "developing the municipality through science and education", leading the economic and educational development in south region of China.

4.1.2 Meta-synthesis management for the construction project

The objectives of meta-synthesis management for the Guangzhou Higher Education Mega Center Project include first-class planning, first-class design, first-class construction and first-class quality.

The meta-synthesis management systems of the organizations and the associated procedures were determined by taking into account the large scale of the project, short period of time involved, as well as the multiple coordination tasks required for the construction of the Guangzhou Higher Education Mega Center Project, as shown in Figure 7. The government is responsible for organizing project construction headquarters and authorizing social professional institutions to handle transactional and specialized work during the project planning, construction, and operation stages. Through this, centralized leadership can be achieved when managing the whole project.

First of all, such systems avoid the traditional model of construction headquarters which were normally applied in 


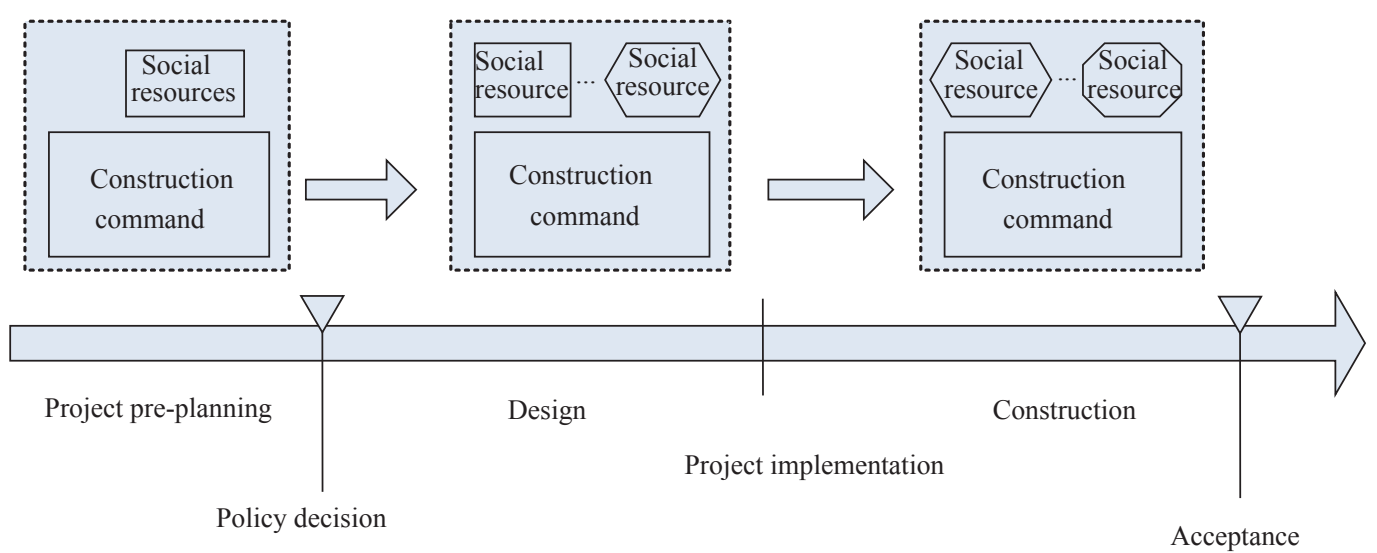

Figure 7. The meta-synthesis management systems of the organizations and procedures for the Guangzhou Higher Education Mega Center Project.

the period of planned economy, preventing construction headquarters from becoming "bloated" as the project progresses. Social resources are also expected to be effectively utilized through these systems so as to achieve socialization and specialization during the project delivery. In addition, highly efficient construction headquarters can better handle different issues occurring during project construction and thus achieve meta-synthesis management. In summary, the all systems are built according the principles of government-led and society-participated, through which the government can actively play a leading role in major public projects. Social resources can also be fully utilized due to effective market allocation.

As a result, robust management systems, socialized management models, standardized management regulations as well as modern management tools were established for the Guangzhou Higher Education Mega Center Project to ensure meta-synthesis management. Project supervision was emphasized for quality control. Project leaders also adopted different measures to achieve the objectives of cost control, including quota design in the design stage, limited price in the tending stage, strict control of engineering change in the construction stage, etc. Through this, meta-synthesis management of the project was successfully achieved.

\subsubsection{Project benefits}

An innovative construction model of "small owners, large systems" was adopted in the management process of the Guangzhou Higher Education Mega Center Project to achieve specialization and socialization in efficiency-oriented urban planning. Such a government-led development path for a modern city also emphasizes intensive construction as well as meta-synthesis management.

Project benefits: the project was completed on schedule and with cost under control. It obtained the Zhan Tianyou Award, the Luban Award, the National High Quality Project Silver Medal, the National Human Habitat Environment
Award, the National Top Ten Construction Science and Technology Achievement Award, the Guangdong Province Science and Technology Progress Award, etc. 22 project outcomes are domestically leading and internationally advanced.

Economic benefits: save 3 billion RMB, 1.26 square kilometers of land, 129 million kilowatt hour of electricity per year, and 16.8 million tons of water per year.

Environmental benefits: reduce $\mathrm{CO}_{2}$ emissions by 936,600 tons per year, carbon emissions of 255,000 tons per year, increasing urban green space by 9.9 square kilometers and transforming clean water by 1.8 square kilometers.

Social benefits: providing advanced construction concepts for building a resource-saving and environment-friendly society.

4.2 The starting area of Guangzhou International Financial City

Guangzhou International Financial City is delivered with the aim to implement the municipal strategy of "strong financial market" as well as to facilitate the development of the regional financial center in Guangzhou. The project is also expected to bring demonstrative effect for developing new urbanization in Guangzhou.

4.2.1 Challenges and risks of the construction of the starting area of Guangzhou International Financial City

First of all, the development scale is large. The planning area of the starting area is 1.32 square kilometers, with $2,136,000$ square meters of underground space being developed. This includes an area of $484,000 \mathrm{~m}^{2}$ for commercial use. Such large-scale development involves lots of work, producing uncontrollable factors. Secondly, there are many investors involved in the areas of finance, water supply, transportation, etc. It could be a big challenge to effectively organize those investors and thus achieve comprehensive development. Thirdly, many construction units participate in the project 


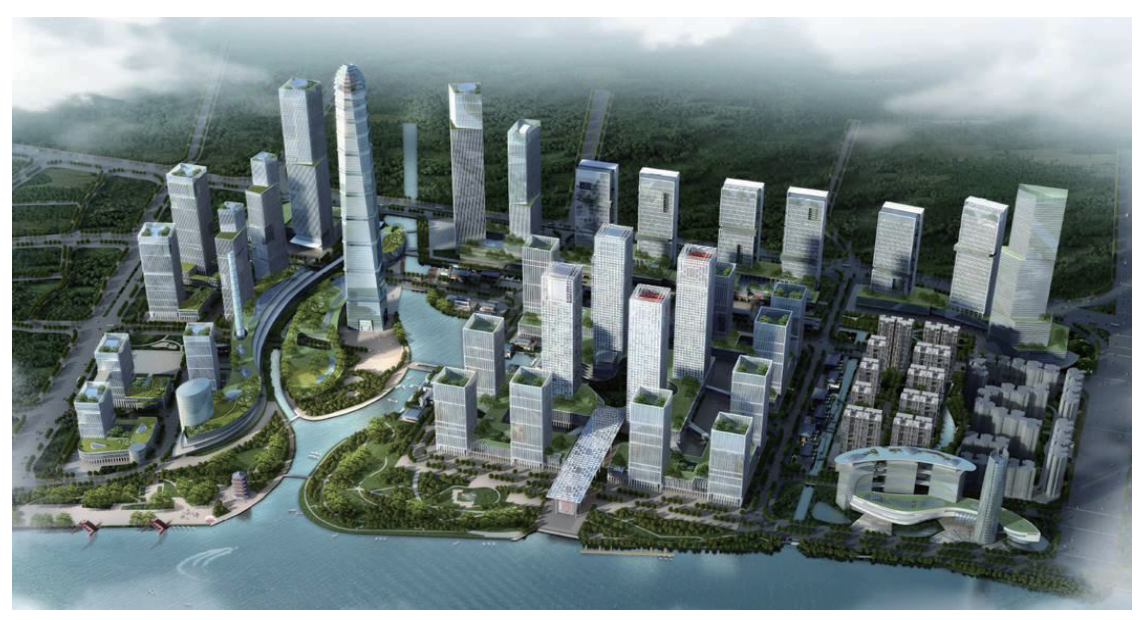

Figure 8. Urban design of the starting area of Guangzhou International Financial City.

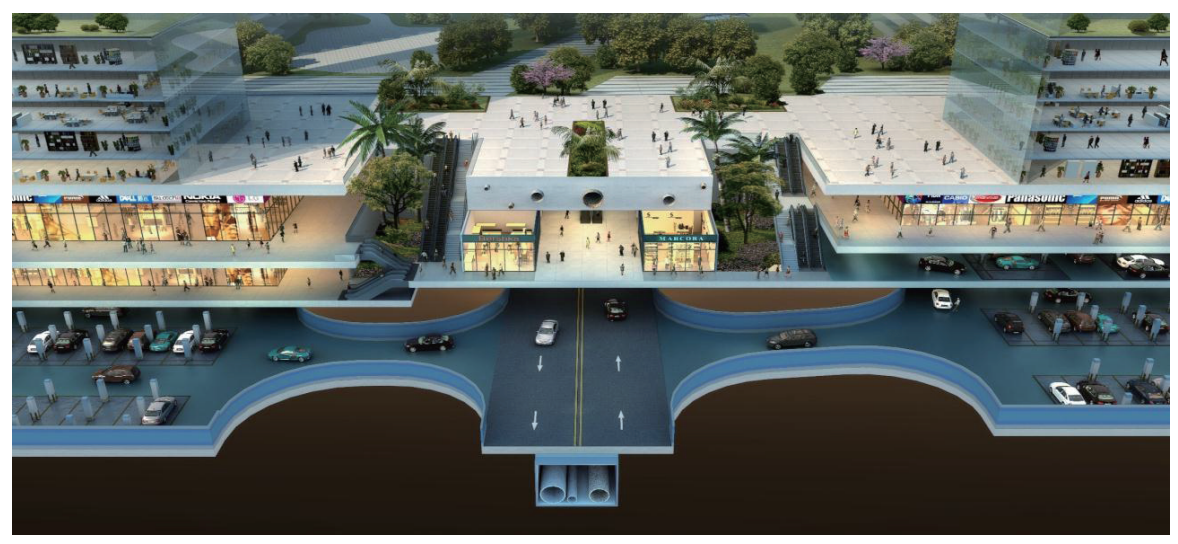

Figure 9. Vertical design of the starting area of Guangzhou International Financial City.

delivery and this may add difficulty to the coordination and organization of work. Fourthly, it is challenging to satisfy multiple operators during the project operation stage. Last of all, diversified professions are involved with regard to the areas of architecture, structure, solid waste treatment, regional energy, transportation, etc, making the whole construction process more complicated and difficult.

4.2.2 Synthesis of construction management objectives of the starting area of Guangzhou International Financial City

The construction concepts of "high-level planning, high-standard construction and high-quality management" were adopted when delivering the starting area of Guangzhou International Financial City so as to achieve the objectives of "unified planning, unified purchasing and storage and unified transfer". By breaking down implementation, the whole project is delivered in a comprehensive manner. The meta-synthesis management objectives of the starting area of Guangzhou International Financial City were established as "integrated overall layout, enhanced green construction, exquisite quality management and standardized civilized construction". A low-carbon and green, smart and intelligent financial city is expected to be built with world standard of transportation and service.

4.2.3 Synthesis of construction management organizations of the starting area of Guangzhou International Financial City

Efficient organization and management mechanisms were adopted regarding the main body of project management. A leading group of financial city development was established responsible for making decisions on investment direction and promoting project implementation. The government construction management organizations played a core role when delivering the project, coordinating the work of various administrative departments. According to the law, contracts were signed through tenders, based on which synthesis of organizations was developed. The implementation of reward and punishment mechanisms, on the other hand, has facilitated the smooth delivery of the project. Meanwhile, an internet-based project management platform was built so 
that all units involved in the project can effectively and efficiently share information and exchange data. Through this, the management cost can be reduced and management efficiency can be improved.

4.2.4 Synthesis of construction management procedures of the starting area of Guangzhou International Financial City

(1) Synthesis of decision making and operation

The planning philosophies of "low-carbon economy, smart city, and happy life" were adopted when delivering the starting area of Guangzhou International Financial City. The project emphasized the comprehensive development of the city as well as its underground space. Attention was also paid to the integrated transport services and local culture during project implementation. As a result, special construction management organizations were established by the government to manage the whole project as well as to coordinate the construction of municipal infrastructure and supporting facility. Through this, private investment is expected to be involved in early stages so as to ensure the project proceeds smoothly.

(2) Synthesis of decision making and design

Seven research projects were conducted during the early stage of the project to achieve a rational and comprehensive use of underground space and these include the vertical design of underground space, smart city, regional energy, solid waste treatment, water/renewable energy utilization, comprehensive pipe gallery facilities and disaster prevention systems. Through this, the initial project of Guangzhou International Financial City was expected to achieve the optimal usage rate of the space and thus maximizing its social and economic benefits.

4.2.5 Safeguard measures of meta-synthesis management for the starting area of Guangzhou International Financial City

The project of the starting area of Guangzhou International Financial City is similar to the project of the University City concerning its large construction scale, short construction period, as well as multiple coordination tasks. However, the Guangzhou International Financial City project involves more investors, more construction and operation units and more specialties during delivery. A higher standard was applied with regard to the areas of green technology, energy saving, environmental protection, intelligence, etc. As a result, more innovative, practical and advanced mechanisms of meta-synthesis management have been adopted to achieve the core project objectives of quality, safety, cost, etc. First, unified planning mechanisms were established in urban design, regulatory detailed planning of different lands and special planning of underground space. Secondly, project design was conducted systematically to involve operational units as early as possible. Thirdly, coordination was emphasized to promote the smooth delivery of project with multiple professional units involved. Fourthly, fast and efficient mechanisms for project acceptance were developed. Lastly, an effective working mechanism was established to ensure a seamless connection between project acceptance, transfer as well as operation.

\section{Conclusions}

Innovation in construction management during new urbanization is becoming more and more important to achieve sustainable urban development and to maximize overall project efficiency. The management systems of urban complex construction projects are large and complicated. As a result, this paper has innovatively proposed a government-led meta-synthesis management approach from a multidimensional perspective of project management. Such government-led meta-synthesis management mechanisms have been successfully implemented in some typical urban complex construction projects such as the Guangzhou Higher Education Mega Center project and the Guangzhou International Financial City project, indicating such theoretical innovation from practice is an effective paradigm for achieving government-led meta-synthesis project management.

Government-led urban complex construction projects are the focus of social concern and with the growth of various types of social demands, new issues may continuously arise during project delivery. This requires the government to constantly improve the management level. Future research is therefore needed with regard to the areas of objective positioning and decomposition, evaluation indicator refinement and quantitative analysis, etc. in meta-synthesis management. Through this, more perfect construction project management mechanisms are expected to be established so as to improve the overall efficiency of the project.

\section{References}

Hao, G. (2009). Study on the project life-cycle three-dimensional synthesis management of railway station construction. Railway Economics Research, 6, 30-35

Wen, H. (2010). Urban planning and urban sustainable development. Impact of Science on Society, 13(4), 48-52

Zhang, R. (2009). Mega-projects and city development. Urban Issues, 2, 37-40

Zheng, X., \& Xu, H. (2012). Study on urban sustainable development. Journal of Xi'an University of Architecture \& Technology (Natural Science Edition), 44(1), 82-89 